\title{
A INFLUÊNCIA DOS FATORES PESSOAIS NO DESEMPENHO DOS TRABALHADORES NAS ORGANIZAÇÕES
}

\author{
Renan Harnack (Universidade do Estado de Santa Catarina - UDESC) \\ harnack@outlook.com \\ Valdésio Benevenutti (Universidade do Estado de Santa Catarina - UDESC) \\ valdesio.benevenutti@udesc.br
}

\section{Resumo}

O cenário cada vez mais competitivo entre as organizações provoca a busca por otimizações em todos os setores da empresa. Na esfera da gestão de pessoas não seria diferente: os indivíduos são as peças chave para a obtenção da excelência organizacional. Entretanto analisar pessoas é uma missão árdua devido as diversas variáveis únicas existentes em cada ser. A otimização do trabalhador, também chamado de grau ou índice de desempenho é atualmente uma das grandes oportunidades de desenvolvimento nas organizações. Assim, deve-se não somente mapear fatores que proporcionam variabilidades no desempenho referentes ao ambiente interno da empresa, mas também entender como os eventos ligados à vida pessoal do colaborador podem causar esta volubilidade. Desta maneira, este trabalho buscou identificar os fatores de maior relevância do ambiente externo que impactam no desempenho dos indivíduos dentro das organizações. Para isto, foi elaborado e aplicado um questionário obtendo informações que, quando analisadas mostraram o comportamento das oscilações de desempenho. Por consequência, encontrou-se os pontos críticos de queda ou aumento da performance do trabalhador que precisam ser observados com maior afinco pelo setor da gestão de pessoas para que assim, se aprimore o potencial do indivíduo e consequentemente o crescimento da organização.

Palavras-Chaves: Desempenho. Fatores pessoais. Organizações. Trabalhadores.

\section{Introdução}

O maior patrimônio de uma empresa são as pessoas e seu conhecimento. Este por sua vez, é intangível, agregando valor e vantagem competitiva para a organização. Desta forma, pode-se dizer que uma organização é resultado de um trabalho em equipe com um objetivo comum. (ANDRADE, 2012a).

Segundo pesquisa da Isma Brasil (2015), realizada em 3 grandes capitais brasileiras, 72\% dos trabalhadores estão insatisfeitos com seus trabalhos, o que revela uma das grandes dificuldades 
das organizações no desenvolvimento das pessoas, que é, o de entender o conceito de realização pessoal para cada indivíduo.

Este alto índice de insatisfação é preocupante para qualquer organização. Segundo Gandolpho (2010), após um estudo feito pela Consultoria Right Management envolvendo 30 mil pessoas de 15 países, foi concluído que pessoas motivadas são 50\% mais produtivas, ou seja, há um grande gap que precisa ser melhorado para que as organizações possam conseguir um maior desempenho.

Diante deste cenário, como os eventos cotidianos fora do ambiente organizacional influenciam o desempenho dos trabalhadores?

Assim, o objetivo geral deste trabalho é identificar os fatores de maior relevância do ambiente externo que impactam no desempenho dos indivíduos dentro das organizações.

Os objetivos específicos são:

- Identificar se a convivência familiar possui influência no comportamento do indivíduo dentro da organização;

- Verificar se o estado da situação financeira do colaborador impacta em seu desempenho;

- Analisar a relação entre a vida social do trabalhador e seu desempenho na empresa;

- Investigar como a saúde do colaborador influencia na execução de tarefas dentro da organização;

- Descrever como a segurança pública impacta no desempenho do trabalhador.

\section{As organizações e as influências no comportamento humano}

As organizações são compostas por pessoas que apresentam necessidades diferentes. Estes indivíduos cooperam entre si para atingir certos objetivos, sejam estes individuais ou coletivos (HOFSTEDE, 2001).

Lawler (1996) afirma que as pessoas são uma das três maiores fontes de vantagem competitiva mais poderosas para a organização. As empresas estão em constantes transformações, ocasionando um profundo impacto nas pessoas, alterando assim, suas formas de gerenciar e agir dentro das organizações. 
De acordo com Bispo (2006), os fatores externos de influência são os que têm origem fora do âmbito da empresa, mas que exercem influência direta no comportamento, ações e decisões dos trabalhadores dentro da empresa, por isso não podem ser desprezados. Esses fatores estão de certa forma, ligados a qualidade de vida pessoal, e são classificados em convivência familiar, situação financeira, vida social, saúde e segurança pública

\subsection{A influência da convivência familiar}

A família exerce uma influência significativa durante todo o processo de desenvolvimento do indivíduo (BIASOLI-ALVES, 2004).

Essas influências de acordo com Sudbrack (2001) variam de acordo com as mudanças que ocorrem em cada família, podendo ser afetadas tanto por eventos críticos previsíveis (casamento, adolescência dos filhos), quanto por eventos críticos não previsíveis (doenças, perdas). Tais acontecimentos apresentam grande impacto no contexto familiar, afetando direta ou indiretamente todos os seus membros. Um exemplo seria o período da adolescência, que provoca intensas mudanças relacionais, especialmente entre pais e filhos.

Segundo Cerveny e Berthoud (2002), pais e filhos possuem diferentes perspectivas sobra a vida. Os adolescentes costumam questionar valores e regras familiares, preocupando-se com o futuro, já os pais se encontram em uma etapa de questionamento profissional, de reflexão e de transformação, também repensando o futuro.

Quando o assunto é o matrimônio, Reis, Hernandes e Gomes (2010) comentam que o mesmo tem sido tratado como uma questão de saúde para o casal e para a família, sendo apontado como fator de proteção para doenças orgânicas, transtornos mentais, fonte de apoio social e um ótimo meio para combater o estresse.

\subsection{A influência da situação financeira}

Andrade (2012b) afirma que o fato de se ter problemas na situação financeira influencia na avaliação que o trabalhador faz de sua qualidade de vida. Oliveira (2015) acrescenta que estar 
mal financeiramente causa preocupações, estresse e desmotivação impactanto diretamente no desempenho do indivíduo.

A impossibilidade de investir em lazer, informação e cultura devido a uma situação financeira precária é um dos aspectos que mais afetam negativamente a vida dos trabalhadores (PENTEADO e PEREIRA 2007).

Segundo o The Economist (2005), a renda pessoal, dentre nove indicadores estudados, é o critério de maior importância e influência na satisfação pessoal para 24 dos 28 países abordados.

\subsection{A influência da vida social}

Os seres humanos são essencialmente seres sociais e instintivamente motivados por uma necessidade de se relacionar (CARVALHO, 2009).

Para Silva et al. (2008) toda relação interpessoal mobiliza processos psíquicos. O indivíduo convive e se relaciona com outras pessoas em diferentes lugares, formando grupos por afinidades e aproximações como família, escola, igreja e trabalho. Leitão, Fortunato e Freitas (2006) acrescentam que as condições em que ocorrem esses relacionamentos definem a forma de convivência entre os seres humanos. E são estas condições que fazem a diferença entre o mal e o bem-estar na vida social, e em como ela é construída no dia-a-dia.

Dante e Arroyo (2017) afirmam que a influência social dos colaboradores está diretamente relacionada às suas carreiras, necessidades, expectativas e visões. Möller (1996) complementa que ao se ter boas relações pessoais gera um sentimento de satisfação a respeito de si mesmo e a se entender bem com os outros.

Para Costa e Widiger (2002), pessoas com alta socialização tendem a ser generosas, bondosas, sorridentes, prestativas e altruístas. Possuem um certo desejo e satisfação em ajudar aos outros, e tendem também, a serem assertivas e empáticas.

Os fatores que mais influenciam segundo Brondani (2010) são o respeito, a amizade, a cordialidade nas relações, a cooperação e o entrosamento. As pessoas levam para o trabalho valores, crenças e expectativas pessoais e são as suas emoções e sentimentos que interferem no seu desempenho organizacional. 


\subsection{A influência da saúde}

De acordo com Minayo, Assis e Oliveira (2011) alguns problemas de saúde se desencadeiam devido ao estilo de vida de cada pessoa. A alimentação desbalanceada, irregularidade na rotina do sono e o sedentarismo por exemplo, são fontes de diversos problemas de saúde a médio e longo prazo.

Para Pellegrini (2017), o estresse causado pela falta de saúde, diminui o desempenho do trabalhador e aumenta os custos das organizações com problemas de saúde, com o aumento do absenteísmo, da rotatividade e do número de acidentes no local de trabalho.

Ainda sobre a saúde mental, a WHO (2002), ressalta que os transtornos mentais menores atacam aproximadamente $30 \%$ dos trabalhadores, e os transtornos mentais graves, entre 5 e $10 \%$.

Países como o Brasil e outros da América Latina, a péssima distribuição de renda, o analfabetismo e o baixo grau de escolaridade, assim como as condições precárias de habitação e ambiente têm um papel muito importante nas condições de vida e saúde (MINAYO, ASSIS e OLIVEIRA, 2011).

\subsection{A influência da segurança pública}

Sentir-se seguro, para Lourenço (2009) está diretamente ligado a qualidade de vida do indivíduo, indicando que a mesma impacta no desempenho do trabalhador.

$\mathrm{O}$ autor ainda defende que a falta de segurança traz problemas para o indivíduo gerando o sentimento de medo, sendo este o maior fator incapacitante para uma pessoa. Além disto, a insegurança pode gerar distúrbios na saúde do indivíduo, como a dependência em outras pessoas, crises de pânico, ansiedade e depressão (LOURENÇO, 2009).

\section{Metodologia}


A primeira etapa da pesquisa foi a realização de uma revisão bibliográfica, através da seleção de livros, artigos, dissertações, revistas e sites. Este processo teve como objetivo levantar todo o embasamento teórico necessário para o desenvolvimento das demais etapas e da definição da metodologia utilizada.

Como segundo passo elaborou-se um protocolo para ser seguido na criação de um questionário que foi testado com 10 pessoas pertencentes ao público alvo a fim de corrigir e ajustar as perguntas e as opções de respostas.

A terceira etapa é caracterizada pela pesquisa de campo, com a aplicação do questionário definitivo no período de 08/04/2019 à 07/05/2019 junto ao público alvo com a participação de 94 pessoas.

Por fim, foi feita a análise e a apresentação dos dados, realizado por meio da interpretação das respostas obtidas.

\section{O perfil socioeconômico dos participantes da pesquisa}

O Quadro 1 apresenta os resultados obtidos do perfil da amostra da pesquisa realizada.

Quadro 1 - Perfil Socioeconômico

\begin{tabular}{|clrl|}
\hline Indicadores & & Quantidade \\
\hline $\begin{array}{c}\text { Identidade de } \\
\text { gênero }\end{array}$ & Masculino & 53 & $(56,4 \%)$ \\
& Feminino & 41 & $(43,6 \%)$ \\
\hline \multirow{2}{*}{ Faixa Etária } & 18-25 anos & 36 & $(38,3 \%)$ \\
& $26-30$ anos & 37 & $(39,4 \%)$ \\
& $36-40$ anos & 10 & $(10,6 \%)$ \\
& $41-45$ anos & 9 & $(9,6 \%)$ \\
& Namorando(a) & 2 & $(2,1 \%)$ \\
& Solteiro(a) & 35 & $(37,2 \%)$ \\
Estado Civil & Morando junto com o(a) parceiro(a) & 29 & $(30,9 \%)$ \\
& Casado(a) & 13 & $(13,8 \%)$ \\
& Divorciado(a) & 13 & $(13,8 \%)$ \\
& Nenhum & 4 & $(4,3 \%)$ \\
\hline \multirow{5}{*}{ Número de } & 2 (dois) & 70 & $(74,5 \%)$ \\
filhos & 3 (três) & 10 & $(10,6 \%)$ \\
& 4 (quatro) & 7 & $(7,4 \%)$ \\
& Mais que quatro & 3 & $(3,2 \%)$ \\
& & 3 & $(3,2 \%)$ \\
& 1 (um) & $(1,1 \%)$
\end{tabular}




\begin{tabular}{|c|c|c|}
\hline \multirow{7}{*}{$\begin{array}{l}\text { Renda } \\
\text { Mensal }\end{array}$} & Até $\mathrm{R} \$ 998,00$ & $11(11,6 \%)$ \\
\hline & Entre $R \$ 999,00$ a $R \$ 2994,00$ & $35(37,2 \%)$ \\
\hline & Entre $R \$ 2995,00$ a $R \$ 4990,00$ & $25(26,6 \%)$ \\
\hline & Entre $R \$ 4991,00$ a $R \$ 6986,00$ & $14(14,9 \%)$ \\
\hline & Entre $\mathrm{R} \$ 6987,00$ a $\mathrm{R} \$ 8982,00$ & $4(4,3 \%)$ \\
\hline & Mais que $\mathrm{R} \$ 8982,00$ & $4(4,3 \%)$ \\
\hline & Preferiu não informar & $1(1,1 \%)$ \\
\hline \multirow{3}{*}{$\begin{array}{l}\text { Segmento em } \\
\text { que atua }\end{array}$} & Indústria & $51(54,2 \%)$ \\
\hline & Serviços & $31(33,0 \%)$ \\
\hline & Comércio & $12(12,8 \%)$ \\
\hline
\end{tabular}

Fonte: Elaborado pelos autores, 2019

Os resultados da amostra obtida refletem porcentagens semelhantes as fornecidas pelo IBGE (2018), com exceção à faixa etária.

\subsection{O impacto da convivência familiar}

Neste tópico é abordado as variáveis estabelecidas relacionadas à convivência dos pesquisados com suas respectivas famílias. Os Indicadores abordados são a vivência com o(a) parceiro(a) e com os filhos. Em relação a outros possíveis indivíduos como pais, avós, dentre outros e de animais domésticos como cães e gatos que possam ter convívio com o trabalhador, não foram abordados explicitamente no questionário aplicado. A primeira pergunta desta categoria indicada na Figura 1, trata do relacionamento com a pessoa amada.

Figura 1a - Nível do contentamento da convivência com companheiros(as)

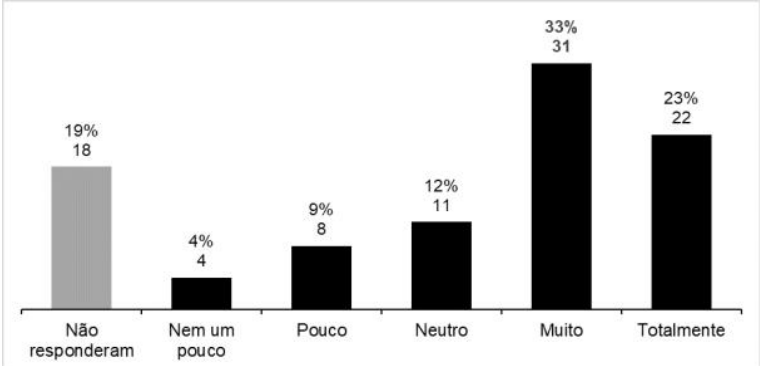

Figura 1b - Grau de influência no desempenho do trabalho

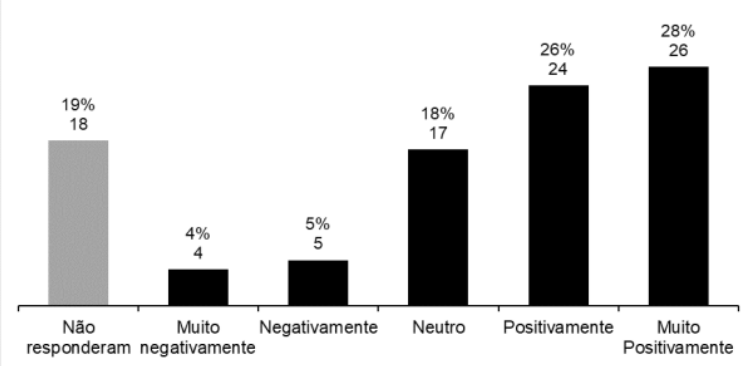

Fonte: Elaborado pelos autores, 2019 
Abordou-se questões como diálogo, afeição, brigas, momentos íntimos e a parceria entre o casal. Dos trabalhadores que possuem algum tipo de relacionamento no período da aplicação da pesquisa, boa parte diz estar bem em seus relacionamentos e isto os dá uma determinação maior perante as atividades em seus ofícios. Entretanto, os que relataram não estarem tão bem com seus parceiros também apontam uma grande queda em seus desempenhos.

Em relação a vivência com os filhos, o mesmo problema visto no indicador sobre qualidade na educação aparece: a baixa quantidade de respostas devido a amostra estudada indicada na Figura 2.

Figura 2a - Nível do contentamento da convivência com os filhos

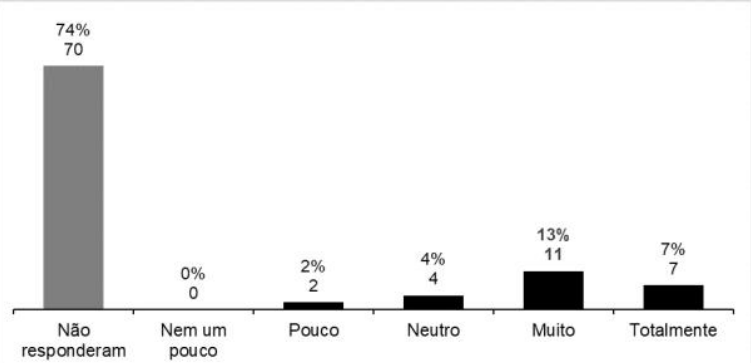

Figura $2 b$ - Grau de influência no desempenho do trabalho

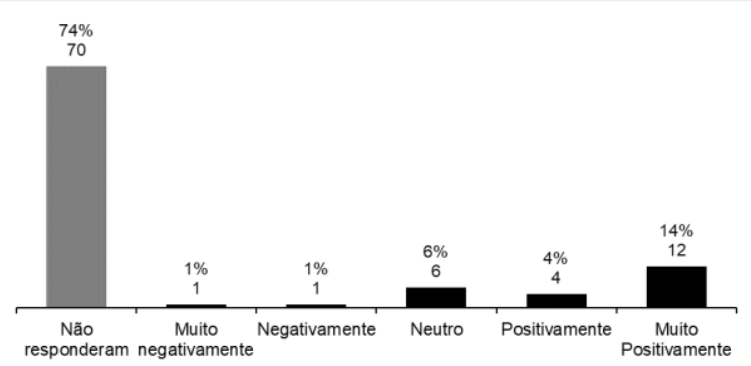

Fonte: Elaborado pelos autores, 2019

Das respostas obtidas, percebe-se que um bom relacionamento com as crianças traz benefícios no rendimento das atividades de trabalho, entretanto devido a precariedade de informações, o resultado dessa variável não deve ser tomado como algo preciso e, fica evidente a necessidade de se realizar uma nova pesquisa com este indicador para poder validá-lo.

\subsection{O impacto da situação financeira}

Para esta categoria, a fim de mensurar como a situação financeira do trabalhador o influencia, foi abordado não somente seus ganhos e endividamentos, mas também seu patrimônio, como residência, veículos, vestuários, dentre outros. Os resultados são ilustrados pela Figura 3. 
Figura 3a - Satisfação com a situação financeira e bens materiais

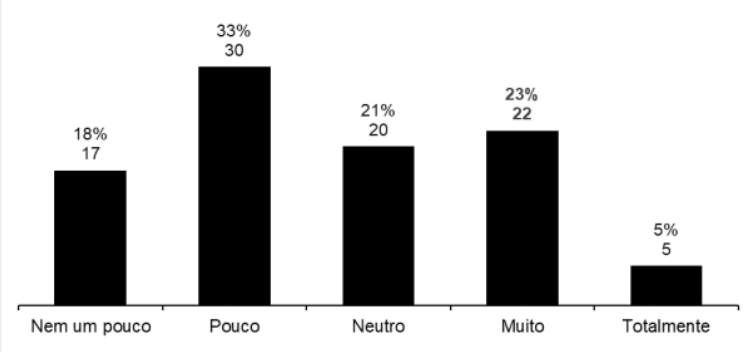

Figura 3b - Grau de influência no desempenho do trabalho

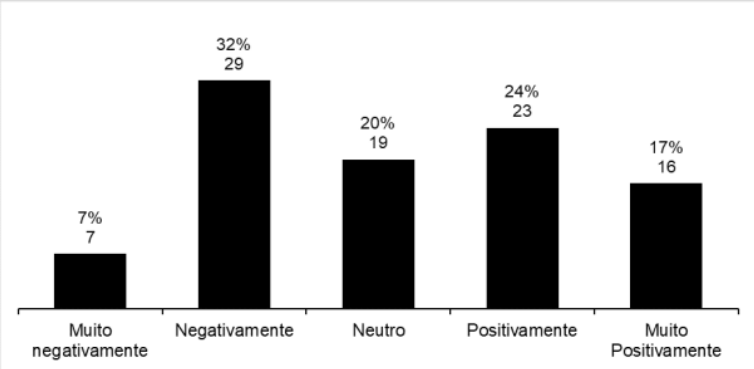

Fonte: Elaborado pelos autores, 2019

Mais da metade das respostas mostram um descontentamento com sua atual situação financeira, e isto trás 2 consequências: uma parte alega o decaimento de seu desempenho devido a isto, e a outra um aumento da mesma, procurando um aumento salarial e assim por suas finanças em ordem. Já para os que estão satisfeitos com seus bens, os dados mostram nenhuma interferência ou um certo aumento de eficiência por parte dos trabalhadores.

\subsection{O impacto da vida social}

Neste tópico, foi abordado em uma pergunta questões como a satisfação da vida social do pesquisado, bem como seu sentimento em relação ao nível social, intelectual e cultural, sua religiosidade e suas atividades em seu tempo livre. A Figura 4 mostra os resultados obtidos pela amostra para este quesito.

Figura 4a - Satisfação com o convívio social

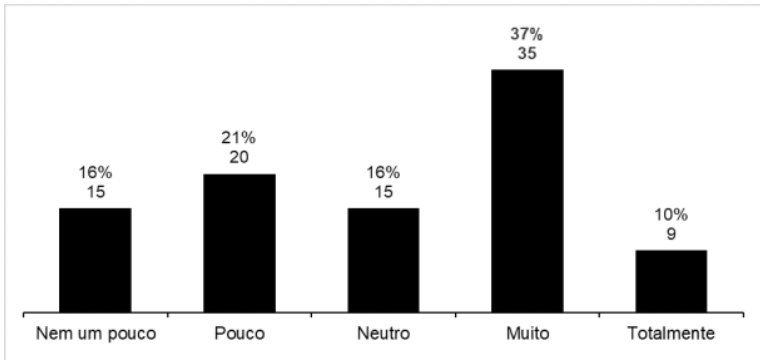

Figura 4b - Grau de influência no desempenho do trabalho

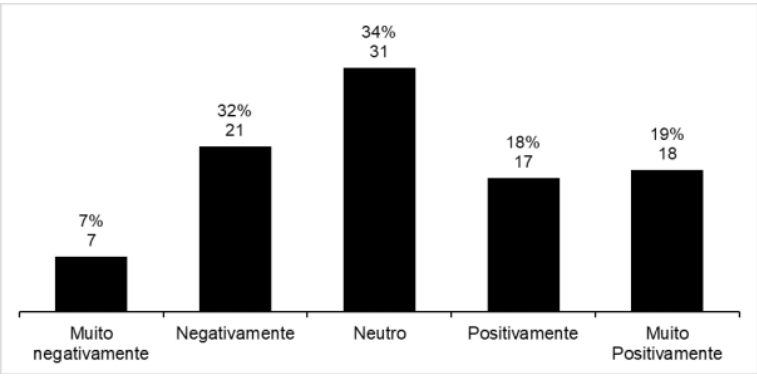

Fonte: Elaborado pelos autores, 2019

Aqueles que responderam estar insatisfeitos, relatam a perda de vontade de realizar suas tarefas, fazendo assim com que seus desempenhos dentro do local de trabalho diminuam. Por sua vez, os que estão bem com esta variável, assinalaram que isto não os impacta muito em seu desempenho, que tende a ser o mesmo ou aumentar sutilmente. 


\subsection{O impacto da saúde}

No quesito da saúde, realizou-se uma pergunta (Figura 5) envolvendo o contentamento com o estado físico e mental do indivíduo. Neste ponto entram fatores como práticas desportivas, uma dieta saudável e possíveis distúrbios neurológicos.

Figura 5a - Satisfação com o estado físico e mental

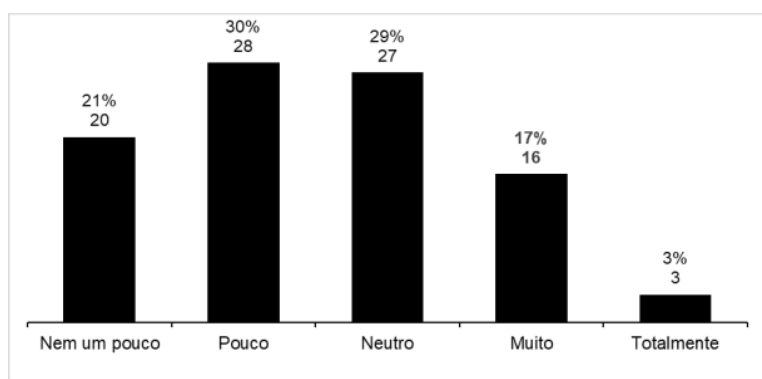

Figura $5 b$ - Grau de influência no desempenho do trabalho

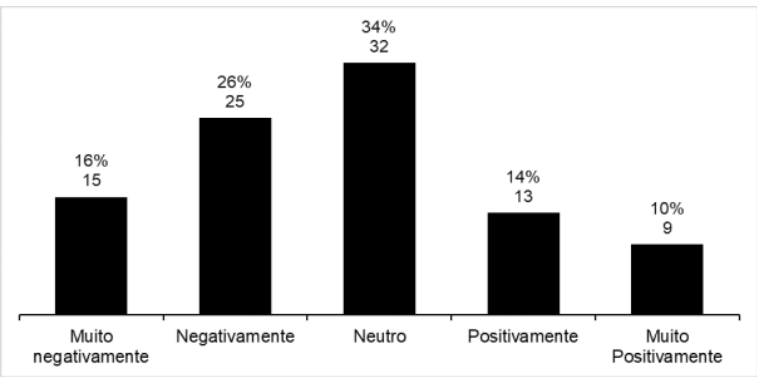

Fonte: Elaborado pelos autores, 2019

Nota-se que metade dos pesquisados afirmam não estarem satisfeitos com seus estados físicos e mentais. Quanto ao estado físico, uma parcela dos descontentes que não dependem do seu físico para realizar suas atividades em seus trabalhos dizem que este fator não interfere em seus desempenhos, já a outra, relata a perca de performance em seus afazeres. E se tratando da plenitude mental, aqueles que indicaram insatisfações com a mesma, também afirmam grande perca de rendimento em suas atividades.

\subsection{O impacto da segurança pública}

Por fim, o último tópico analisa como a segurança pública interfere no desempenho do trabalhador. Para isto foram realizadas quatro perguntas envolvendo as variáveis da qualidade da segurança pública, impunidade e corrupção de problemas com a violência.

Para a variável da segurança pública, conforme a Figura 6, o descontentamento foi quase unânime. Dos 5 casos que afirmaram estar totalmente satisfeitos com a mesma, 4 moram no estrangeiro e se referiram a qualidade de seus respectivos países. 
Figura 6a - Satisfação com o atual estado da segurança pública

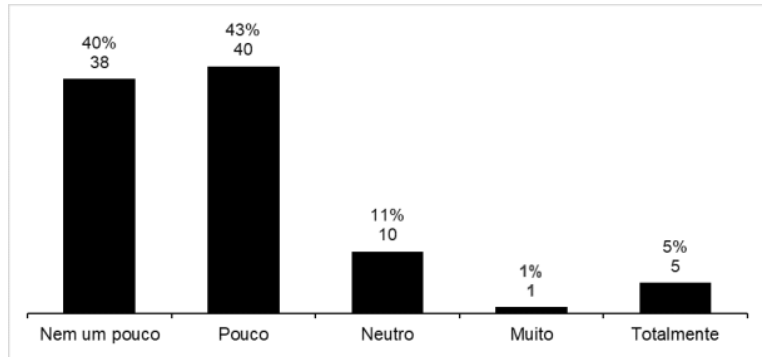

Figura $6 b$ - Grau de influência no desempenho do trabalho

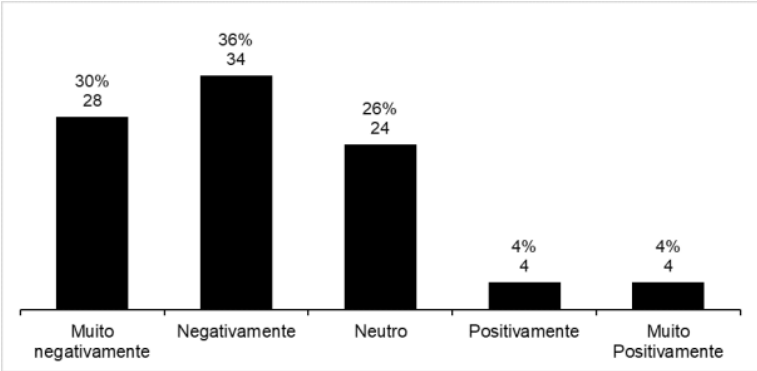

Fonte: Elaborado pelos autores, 2019

Este descontentamento reflete em algumas respostas de neutralidade em suas eficiências e na maioria, sobretudo com os participantes do sexo feminino, há a afirmação de que a situação de precariedade da segurança afeta em muito os seus rendimentos no trabalho. Desta maneira pode-se concluir que o medo a sensação de estar desprotegido são fatores críticos na queda de desempenho do trabalhador.

A segunda pergunta abordada diz respeito ao quanto a corrupção e a impunidade alteram o estado de ânimo do indivíduo. A Figura 7 evidencia as respostas coletadas desta questão bem como o seu impacto no desempenho do trabalho.

Figura 7a - Alteração do estado de ânimo em relação a corrupção e a impunidade

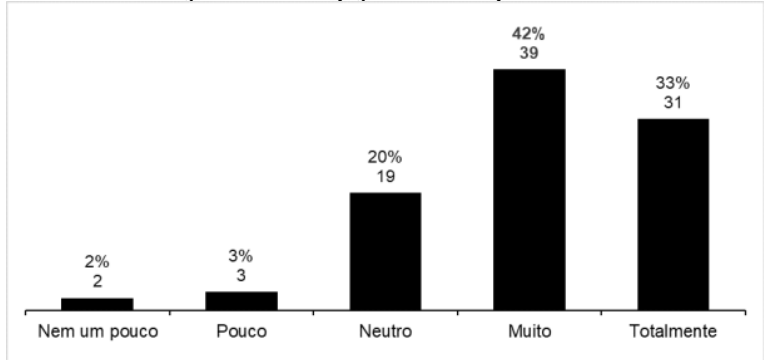

Figura $7 b$ - Grau de influência no desempenho do trabalho

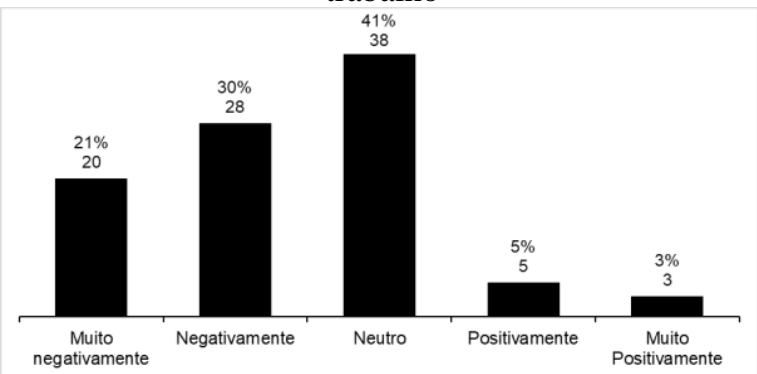

Fonte: Elaborado pelos autores, 2019 
O resultado indicou que mais de dois terços tem seus temperamentos modificados por este quesito. Em comparação ao desempenho, uma parte destes dizem que isto é algo neutro em suas performances e a outra afirma certa queda na realização de suas atividades.

A próxima variável estudada tem foco em como a violência altera o sentimento do trabalhador. Para 90\% dos participantes da pesquisa, existe alguma alteração, como mostra a Figura 8. Para um quarto destes, isto não reflete em sua performance, entretanto para praticamente todo o restante, isto é um fator de queda de desempenho. Observou-se também, uma grande correlação com os motivos que levam a baixa eficiência das atividades exercidas no trabalho desta pergunta com os da segurança pública.

Figura 8a - Alteração do estado de ânimo em relação a violência

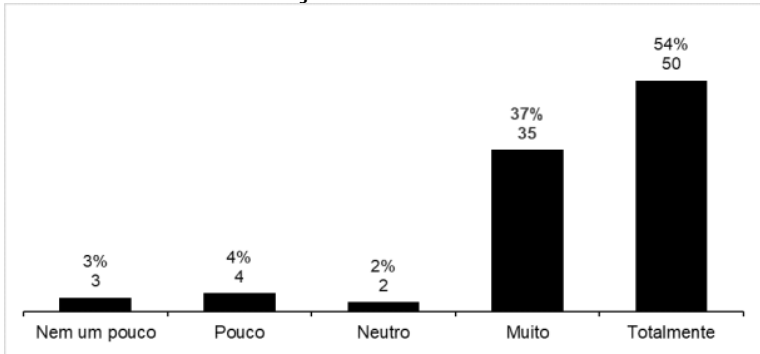

Figura $8 b$ - Grau de influência no desempenho do trabalho

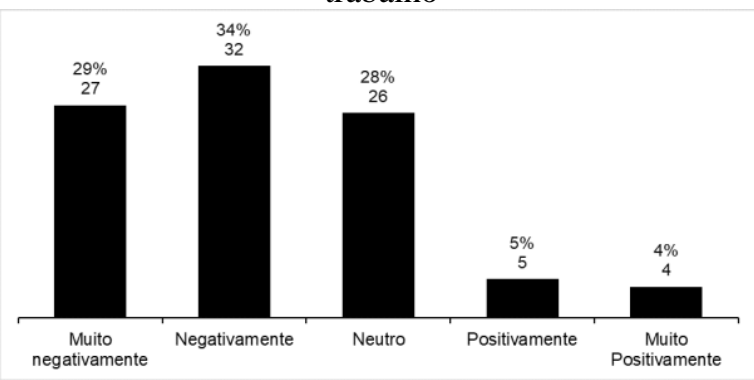

Fonte: Elaborado pelos autores, 2019

Desta forma, pelos resultados obtidos das quatro perguntas realizadas sobre o quesito de segurança, entende-se que os eventos envolvendo esta variável devem ser tratados minuciosamente visto que os mesmos possuem um grande impacto negativo no desempenho dos trabalhadores.

\section{Considerações Finais}

O presente trabalho teve como objetivo identificar os fatores de maior relevância do ambiente externo que impactam no desempenho dos indivíduos dentro das organizações.

Para isto, iniciou-se uma pesquisa bibliográfica, com o intuito de adquirir o embasamento necessário para criar um formulário que buscasse atender o objetivo proposto. Assim foram levantadas as categorias: convivência familiar, situação financeira, vida social, saúde e segurança pública. $\mathrm{O}$ formulário foi aplicado e após, refinado para uma versão final, corrigindo os possíveis problemas do mesmo. 
Dentre as categorias notou-se que questões envolvendo um longo prazo, geralmente possuem uma oscilação moderada no desempenho do trabalhador, seja para mais ou menos.

Possuir um bom convívio com os familiares, amigos e com o parceiro(a) mostra um aumento significativo de performance. Já se existirem problemas nestes quesitos, consequentemente haverá uma certa perda de desempenho.

Tratando-se da renda e situação financeira, há uma grande oscilação caso o indivíduo esteja insatisfeito com a mesma. Uma parte sente-se desmotivada e a outra trabalha arduamente para conseguir uma promoção e reverter a situação.

Os trabalhadores que relatam problemas com sua saúde indicam uma boa queda de suas eficiências, enquanto para aqueles que dizem estarem bem ou indiferentes com a mesma tem poucas oscilações em seus desempenhos.

Por fim, questões envolvendo o sentimento de segurança, levam a uma grande perca de desempenho para aqueles que possuem de alguma forma, preocupações com este quesito.

Portanto, com o estudo das variáveis propostas que interferem nas atividades dos trabalhadores dentro da organização, foi possível compreender o grau de influência do ambiente externo para cada uma destas variáveis sobre o potencial do indivíduo.

\section{REFERÊNCIAS}

ANDRADE, R. M. Qualidade de vida no trabalho dos colaboradores da empresa Farben S/A indústria química. 2012. Monografia (Especialista em Gestão Empresarial) - Universidade do Extremo Sul Catarinense, UNESC, Criciúma 2012a.

ANDRADE, V. et al. Qualidade de vida de servidores técnico-administrativos: um estudo de caso. Revista da Universidade Vale do Rio Verde, v. 10, n. 1, p. 304-312, 2012 b.

BIASOLI-ALVES, Z. M. M. Pesquisando e intervindo com famílias de camadas diversificadas. Pesquisando a família: Olhares contemporâneos, p. 91-106, 2004.

BISPO, C. A. F. Um novo modelo de pesquisa de clima organizacional. Production, v. 16, n. 2, p. 258-273, 2006. BRONDANI, J. P. Relacionamento Interpessoal e o trabalho em equipe: uma análise sobre a influência na qualidade de vida no trabalho. 2010.

CARVALHO, M. do C. N. de. Relacionamento Interpessoal: como preservar o sujeito coletivo. Rio de Janeiro: LTC, 2009. 
CERVENY, C. M. de O.; BERTHOUD, C. M. E. Visitando a família ao longo do ciclo vital. Casa do Psicólogo, 2002.

COSTA, P. T.; WIDIGER, T. A. Introduction: Personality disorders and the five-factor model of personality. Personality disorders and the five-factor model of personality, p. 3-14, 2002.

DANTE, F. S.; ARROYO, R. F. Âncoras de carreira: por onde caminham as gerações? Revista de Carreiras e Pessoas (ReCaPe). ISSN 2237-1427, v. 7, n. 2, 2017.

GANDOLPHO, C. Funcionário motivado produz até 50\% mais. Diário do Grande ABC, São Bernardo do Campo, 26 de abri. de 2010. Disponível em: < www.dgabc.com.br>. Acesso em: 5 de abr. de 2019.

HOFSTEDE, G. Culture's consequences: Comparing values, behaviors, institutions and organizations across nations. Sage publications, 2001.

IBGE. Censo Demográfico, 2018. Disponível em: <www.ibge.gov.br> Acesso em: 12 mai. 2019.

ISMA Brasil. Sem ânimo para ir trabalhar. Recife, 17 de mai. 2015. Disponível em: < www.ismabrasil.com.br/img/estresse54.pdf >. Acesso em: 5 de abr. de 2019.

LAWLER, I. I. I. Competencies: A poor foundation for the new pay. Compensation \& Benefits Review, v. 28, n. 6, p. 20-21, 1996.

LEITÃO, S. P.; FORTUNATO, G; DE FREITAS, A. S. Relacionamentos interpessoais e emoções nas organizações: uma visão biológica. Revista de Administração Pública, v. 40, n. 5, p. 883-908, 2006.

LOURENÇO, N. Segurança, Sentimento de Insegurança e Estado de Direito. O Espectro axial da relação Direitos, Liberdades e Garantias e Poderes do Estado. 2009.

MINAYO, M. C. de S.; ASSIS, S. G. de; OLIVEIRA, R. V C. de. Impacto das atividades profissionais na saúde física e mental dos policiais civis e militares do Rio de Janeiro (RJ, Brasil). Ciência \& Saúde Coletiva, v. 16, p. 2199-2209, 2011.

MÖLLER, C. Employeeship: como maximizar o desempenho pessoal e organizacional. São Paulo: Pioneira, 1996.

OLIVEIRA, G. C. de. Finanças pessoais e qualidade de vida no trabalho dos Servidores: um estudo aplicado a uma Instituição Federal de Ensino. 2015. Dissertação de Mestrado. Universidade Federal do Espírito Santo.

PELLEGRINI, T. Realismo: a persistência de um mundo hostil. Revista brasileira de literatura comparada, v. 11, n. 14, p. 11-36, 2017.

PENTEADO, R. Z.; PEREIRA, I. M. T. B. Qualidade de vida e saúde vocal de professores. Revista de Saúde Pública, v. 41, p. 236-243, 2007.

REIS, A. L. P. P. dos; HERNANDES, S. R. P.; GOMES, A. F. Stress and psychosocial factors. Psicologia: Ciência e Profissão, v. 30, n. 4, p. 712-725, 2010.

SILVA, D. M. da et al. A Importância do Relacionamento Interpessoal no contexto Organizacional. In: Instituto Brasileiro de Pós-Graduação e Extensão-IBPEX-V CONVIBRA-Congresso Virtual Brasileiro de Administração, Universidade Federal da Grande Dourados-UFGD. 2008.

SUDBRACK, M. de F. O. Terapia familiar sistêmica. Dependência de drogas, p. 403-415, 2001. 
THE ECONOMIST Intelligence Unit. The Word in 2005. Quality of Life Index. The Economist, 2005. Disponível em: <www.economist.com> Acesso em: 20 abr. de 2019.

WHO - World Health Organization. Mental disorders, 2002. Disponível em: < www.who.int > Acesso em: 22 abr. 2019. 